\title{
PREVALENCE OF DOMESTIC VIOLENCE IN NIGERIA: IMPLICATIONS FOR COUNSELLING
}

\author{
AIHIE Ose N. PhD \\ School of Education, College of Education, Ekiadolor. Benin.
}

\begin{abstract}
Domestic violence is an issue of global concern. Historically, in many cultures domestic violence has been an accepted fact of life. In recent years, however, it has begun to be viewed as a criminal problem. However, in many societies such as the Nigerian society it is still culturally acceptable. This paper discusses the reported incidence of domestic violence in Nigeria, the different forms of abuse which may occur in the home and the devastating consequences on the individuals involved and the society at large. Some of the predisposing factors of domestic violence are discussed and counselling - preventive and remedial is proffered as a panacea for the ugly phenomenon.
\end{abstract}

Key words: Domestic, violence, abuse, Nigeria, Counselling.

\section{Introduction:}

Domestic violence is the intentional and persistent abuse of anyone in the home in a way that causes pain, distress or injury. It refers to any abusive treatment of one family member by another, thus violating the law of basic human rights. It includes battering of intimate partners and others, sexual abuse of children, marital rape and traditional practices that are harmful to women. Female genital mutilation is a form of domestic violence. Domestic violence occurs globally (Dahlberg and Krug, 2002, UNICEF, 2005). Families from all social, racial economic, educational and religious backgrounds experience domestic violence in different ways. Djaden and Thoennes (2002), report that in the United States of America, each year, women experience about 4.8 million intimate partner-related physical assaults and rapes while men are victims of about 2.9 million intimate partner related physical assaults. In parts of the third world generally and in West Africa, in particular, domestic violence is prevalent and reportedly justified and condoned in some cultures. For instance, $56 \%$ of Indian women surveyed by an agency justified wife-beating on grounds like -bad cook, disrespectful to in-laws, producing more girls, leaving home without informing, among others (Basu and Pratishthan 2002) 
Reports from IRIN (2007) show that $25 \%$ of women in Dakar and Kaolack in Senegal are subjected to physical violence from their partners and that very few admit that they are beaten - while $60 \%$ of domestic violence victims turn to a family member, in three-quarter of the cases, they are told to keep quiet and endure the beatings. The report also reveal that a law passed in the Senegalese penal code punishing domestic violence with prison sentences and fines is poorly enforced due to religious and cultural resistance. In Ghana, spousal assaults top the list of domestic violence (I-RIN, 2007)

In Nigeria, reports reveal "shockingly high" level of violence against women (Afrol News, 2007). Amnesty international (2007) reports that a third (and in some cases two-thirds) of women are believed to have been subjected to physical, sexual and psychological violence carried out primarily by husbands, partners and fathers while girls are often forced into early marriage and are at risk of punishment if they attempt to escape from their husbands. More pathetic is the revelation of gross under reporting and non documentation of domestic violence due to cultural factors (Oyediran and Isugo, 2005, afrolnews, 2007).

This paper examines the incidence of domestic violence in Nigeria, types of domestic violence, consequences of domestic violence and the risk factors. It further proffers suggestions for public enlightenment to remedy the situation through counselling.

\section{Domestic Violence in Nigeria}

Traditionally, in Nigeria, as in many other African countries, the beating of wives and children is widely sanctioned as a form of discipline (UNICEF, 2001). Therefore, in beating their-children parents believe they are instilling discipline in them, much the same way as in husbands beating their wives, who are regarded like children to be prone to indiscipline which must be curbed.

This is especially so when the woman is economically dependent on the man. The society is basically patriarchal and women's place within the scheme is decidedly subordinate. Domestic violence therefore functions as a means of enforcing conformity with the role of a woman within customary society. It therefore does not matter if the woman is economically dependent or not, her position, like that of the children is subordinate.

Violence against women in the home is generally regarded as belonging to the private sphere in Nigeria and is therefore shielded from outside scrutiny. A culture of silence reinforces the stigma attached to the 
victim rather than condemning the perpetrator of such crimes (afrolNews, 2007).

Project alert (2001), in a survey on violence against women conducted interviews with women working in the markets and other places of work and girls and young women in secondary schools and universities, in Lagos state, Nigeria. $64.4 \%$ of 45 women interviewed in the work place said they had been beaten by a partner (boyfriend or husband), 56.6\% of 48 interviewed market woman admitted experiencing such violence. Similar interviews carried out in Oyo state and other parts of Nigeria, yielded similar results. The incidence of domestic violence is high. In a study carried out by Obi and Ozumba (2007), on the factors associated with domestic violence, in South East, Nigeria, $70 \%$ of respondents reported abuse in their family with $92 \%$ of the victims being female partners and the remaining $8 \%$ being male.

The common forms of abuse reported were shouting at a partner $(93 \%)$, slapping or pushing $(77 \%)$ and punching and kicking $(40 \%)$. It is however disturbing to note that many women do not know if they had been abused or not (afrolNews, 2007). This could be due to the acceptance of some abusive behaviour as 'normal'. Oyediran and Isugo (2005), in a study of women's perception of wife-beating in Nigeria, found that $64.4 \%$ and $50.4 \%$ of ever married and unmarried women, respectively, expressed consent for wife beating. Reports in the print and electronic media reveal vicious attacks on women by intimate partners in different forms such as 'acid bath', rape, beatings, some of which sometimes result in the death of the victim. Many victims do not report for fear of reprisal from abusers or the belief that the police and the judicial system cannot help. The police are also reported to frequently dismiss complaints of domestic violence as a 'private matter'.

\section{Types/forms of domestic violence}

There are different forms of abuse a person may be subjected to in the home. They include:

1. Physical abuse

This is the use of physical force in a way that injures the victim or puts him/her at risk of being injured. It includes beating, kicking, knocking, punching, choking, confinement. Female genital mutilation is physical abuse. Physical abuse is one of the commonest forms of abuse. Obi and Ozumba (2007) found that $83 \%$ of respondents in their study reported physical abuse. 
2. Sexual abuse

This includes all forms of sexual assaults, harassment or exploitation. It involves forcing a person to participate in sexual activity, using a child for sexual purposes including child prostitution and pornography. Marital rape also comes under this.

3. Neglect:

This includes failure to provide for dependants who may be adults or children, denying family members food, clothing, shelter, medical care, protection from harm or a sense of being loved and valued.

4. Economic abuse

This includes stealing from or defrauding a loved one, withholding money for essential things like food and medical treatment, manipulating or exploiting family member for financial gain, preventing a loved one from working or controlling his/her choice of occupation.

5. Spiritual Abuse

This includes preventing a person from engaging in his/her spiritual or religious practices or using one's religious belief to manipulate, dominate or control him/her.

6. Emotional Abuse

This includes threatening a person or his or her possession or harming a person's sense of self-worth by putting him/her at risk of serious behavioural, cognitive, emotional or mental disorders. Shouting at a partner which was found to be the most common abuse by Obi and Ozunba (2007) is included. Also included in emotional abuse are name-calling, criticism, social isolation, intimidating or exploitation to dominate, routinely making unreasonable demand, terrorizing a person verbally or physically and exposing a child to violence.

Abuse may occur once, or it may occur repeatedly often in an escalating manner. A person may be subjected to more than one form of abuse.

\section{Consequences of domestic violence (abuse)}

Victims of domestic violence are often in a position of dependence (financial, emotional, physical and otherwise) on the person abusing 
them, for instance, a husband and a wife, children and parents, dependent relatives, aged parents and domestic servants. Children are often principal victims of domestic violence. Witnessing abuse and living in an environment where someone else, usually a care giver is a victim of abuse, can be psychologically devastating for a child. Straus (1994) reports that children who are hit by parents have higher rates of depression than those whose parents disciplined in other ways and are more likely to think about suicides. Some researchers have also found that children whose mothers were abused by their partners have intelligence quotients (IQs) lower than usual (BBC. New Education, 2003).

Violent punishments such as corporal punishment have been found to lead to delinquency in adolescent and subsequently violent crimes. Anikweze (1998) identified violence as a threat to adolescents' well-being. The adolescent may become socialized in violent behaviour. He or she may become confused and angry. The anger may become directed towards either parents or other children. They may become aggressive, becoming troublesome at home and at school. They may also become withdrawn, isolating themselves from others and may underachieve, academically. Victims of domestic violence (whether children or adults) may suffer physical injuries such as minor cuts, scratches and bruises. Others may be more serious and cause lasting disabilities such as broken bones, internal bleeding and head trauma, among others (Dobson, 1984; CDC, 2006).

Some injuries are not physical but emotional. Victims often have low self-esteem, finding it difficult to trust others. The anger and stress experienced by victims may lead to depression and other emotional disorders sometimes leading to suicide (CDC, 2006). Victims may also exhibit harmful health behaviour like excessive smoking, alcohol abuse, use of drugs and engaging in risky sexual activity. An abused child, for instance, may grow up not to trust other people, may go into relationships with an aggressive mode or may become withdrawn, afraid to go into intimate relationship. This usually results in involvement in risky sexual behaviour.

Growing up in an abusive environment is what makes a person find the sight of a suspect being beaten or burnt to death, entertaining and enjoyable. It is what makes the youth happy and excited about being thugs for wicked politicians. Domestic violence gives rise to a violent society because 'charity begins at home". 


\section{Risk Factors.}

Several factors increase the possibility of domestic violence happening, although the presence of these factors do not always mean that domestic violence will take place. CDC (2006) identified the following as risk factors (a) use of drugs or alcohol (b) seeing or being a victim of violence as a child (c) not having a job. This is more so when it is the male partner that is jobless.

Catalano, Lind, Rosenblatt and Novaco (2003) found that increase in unemployment increases the incidence of domestic violence. The author found that the unemployed hypothetically feel frustrated and angry. They labelled this the 'provocative effect' because it shows that unemployment introduces anger into personal relationship that would otherwise be supportive. Other risk factors include tradition and norms within African traditional culture that regard wife battering and harsh disciplining of children as normal. Obi and Ozumba (2007) found that domestic violence was significantly associated with financial disparity in favour of the female, influential in-laws, educated women and couple within the same age group.

\section{Counselling Implications}

To remedy the domestic violence situation in Nigeria, all stakeholders must be involved - the communities, religious groups, institutions, government at all levels. Seminars and workshops, where trained counsellors would assist in propagating the anti-domestic violence campaign, should be organized. There is the need to create awareness at these forums, to underscore the fact that violence in the home serves as a breeding ground for violence in the society.

The need to regard domestic violence from a psychological rather than a socio-cultural perspective should be emphasized. People should be made to understand that adults can change the social norms that justify domestic violence by (1) being role models and working together to end violence in the home (2) modelling non-violent relationship disseminating information which condemns domestic violence

In schools, during Parents' Teachers' Association meetings, the school counsellor could give enlightenment talks, encouraging parents to use disciplinary measures, which are non-violent on their children and avoid exposing children to domestic violent of any form.

Prize-giving day programmes could include short talks on the issue of domestic violence, emphasizing its evil consequences and the need for families to avoid it for a better society. The school counsellor could organize group counselling sessions for the different age groups 
and classes, on the advantages of a violence free society. The boys, in particular should be counselled on how to grow up into 'healthy' men. There are influences within the home, outside the home, from friends, the internet, music and movies - messages that show that a man must be tough and in control in a relationship. The children should be taught how to be assertive without being aggressive. They should be taught how to express anger and frustration without violence. In counselling individual students with anger problem, the various anger management techniques should be taught.

Churches and mosques should organize seminars and outreach programmes where professional counsellors are invited to enlighten the people on the need for a violence free society with the home as the cradle. Young couples planning to get married should be guided on the ways to avoid violence in the intimate relationship of marriage.

The government should establish and fund counselling centres at the community, and Local Government levels and employ professional counsellors to help victims and perpetrators of domestic violence.

\section{References}

AfrolNews (2007) Half of Nigeria's Women experience domestic violence. retrieved May 22, 2008 from http://www.afro.com/ awrticles / 16471

Anikweze C. M. (1998) Threats to adolescent well being. In Orji S.A and C. M. Anikweze (eds.) Adolescent Psychology. 109 - 117.

BBC News Education (2003) Violence at Home hits children's IQ. Retrieved May 2008 from http://news.bbc.co.uk/1/hi/ education/2981312.stm .

Catalano, R; Lind, S, Rosenblatt, A and R Novaco (2003) Research into the Economic antecedents of Violence. American Journal of Community psychology.

CDC (2006) Intimate Partner Violence - fact sheet. Retrieved Oct. 2008 from wwww.Cdc.gov/injury

Dahlberg, L. L. and E. G Krug (2002) Violence - a global public health problem. In King E, Dahlbergl, Meray J. A and A. B Zwi, Lozano R (eds.) World Report on violence and health. Geneva. Switzerland: WHO, 1-56.

Dobson (1984) Dare to Discipline. Weston Illinois: Tyndale House Publishing

Obi, S. N. and B.C. Ozumba (2007) Factors associated with domestic violence in South-East Nigeria. Journal of obstetrics and gynaecology. 27. (1) $75-78$. 
Straus, M. (1994) Beating the devil out of them; Corporal Punishment in American families. New York. Lexington Books

UNICEF (2001) Children and Women's rights in Nigeria: A wake up call situation assessment and analysis. Edited by Hodge. Abuja: National Population Commission and UNICEF.

UNICEF (2005) Violence at home (archive) Voices of Youth Forum. Retrieved Oct. 2008 from http://www.unicef.org/roy/ discussions/archieve/index . 